\title{
Market Definition Alchemy
}

\section{Citation}

Louis Kaplow, Market Definition Alchemy, 57 Antitrust Bull. 915-52 (2012).

\section{Published Version}

http://heinonline.org/HOL/Page?handle=hein.journals/

antibull57\&g_sent $=1 \&$ collection $=$ journals $\& i d=959$

\section{Permanent link}

http://nrs.harvard.edu/urn-3:HUL.InstRepos:32117117

\section{Terms of Use}

This article was downloaded from Harvard University's DASH repository, and is made available under the terms and conditions applicable to Open Access Policy Articles, as set forth at http:// nrs.harvard.edu/urn-3:HUL.InstRepos:dash.current.terms-of-use\#OAP

\section{Share Your Story}

The Harvard community has made this article openly available.

Please share how this access benefits you. Submit a story.

\section{Accessibility}




\section{HARVARD}

JOHN M. OLIN CENTER FOR LAW, ECONOMICS, AND BUSINESS

MARKET DEFINITION ALCHEMY

Louis Kaplow

Discussion Paper No. 746

$05 / 2013$

Harvard Law School

Cambridge, MA 02138

This paper can be downloaded without charge from:

The Harvard John M. Olin Discussion Paper Series:

http://www.law.harvard.edu/programs/olin_center/

The Social Science Research Network Electronic Paper Collection:

http://ssrn.com/ 


\title{
Market Definition Alchemy
}

\author{
Louis Kaplow*
}

\begin{abstract}
In a recent series of articles, I argue that the market definition / market share paradigm should be abandoned entirely. Among my central claims are that: (1) as a matter of economic logic, there exists no valid way to infer market power from the market shares in redefined (non-homogeneous-goods) markets-short of entirely reversing the market redefinition; and (2) choosing a best market requires already having in hand one's best estimate of market power, rendering the exercise pointless-actually worse, since the market power inference from the chosen market is inferior to the estimate with which one began. Not surprisingly, criticisms advanced in this Symposium and elsewhere do not succeed in repealing the laws of logic, any more than medieval alchemists were able to overturn the laws of nature.
\end{abstract}

JEL Classes: D42, K21, L40

Keywords: Market definition, Mergers, Merger guidelines, Hypothetical monopolist test, Competition policy, Antitrust

Recently published, Antitrust Bulletin, vol. 57: 915-52 (2012)

(C) Louis Kaplow. All rights reserved.

* Harvard University and National Bureau of Economic Research. I am grateful to Harvard's John M. Olin Center for Law, Economics, and Business for financial support. This working paper version cites to pre-publication versions of the referenced commentaries. 
Gul: We need gold, and it's hard to make.

Al: Let's use my new technique to turn lead into gold. It may be impure gold that doesn't glisten, but it is gold.

Gul: Well, OK. But, I was wondering, where's the lead? I'm told by our top chemists that there is no good way to make it and we don't have any.

Al: Don't worry. I have also developed a new technique to create lead.

Gul: Fantastic!

We all know Al, a descendant of the alchemists. Gul is from the Gullible clan. Specifically, Gul believes two things that no sensible person could. To be more precise, and to use a bit of license, suppose the following:

1. There is in fact no proper way to turn lead into gold.

2. There is in this world only one way to create lead: one needs gold to do it. Indeed, exactly as much gold as Al claims to be able to make with the lead. Moreover, the gold that $\mathrm{Al}$ claims to be able to produce is lower quality than the gold that must be used to make the lead.

We would be surprised to stumble on a modern civilization that attempted to take Al's advice. Much less one that did so for over half a century.

Two of the central claims of my work on market definition ${ }^{1}$ are that, as a matter of economic logic, contemporary competition discourse-by courts, agencies, economic experts, lawyers, and scholars - is straight out of the Book of Gullible. Specifically —and in this instance literally-I have demonstrated two propositions:

1. There is no proper way to infer market power from market shares in a redefined (non-homogeneous-goods) market.

2. The only_only-legitimate way to choose the best market requires that one use one's best estimate of market power as an input. Moreover, the outputthe market power inference from the best market definition-is less accurate than the best estimate of market power with which one began.

\footnotetext{
${ }^{1}$ Throughout, I refer to Louis Kaplow, Why (Ever) Define Markets?, 124 HARV. L. REV. 437 (2010) [hereinafter Kaplow, Why (Ever) Define Markets?], which is the focus of this symposium, and also Louis Kaplow, Market Definition and the Merger Guidelines, 39 REV. INDUS. ORG. 107 (2011), which applies the analysis to the hypothetical monopolist test in the merger guidelines (see infra Subsection I.D), and Louis Kaplow, Market Share Thresholds: On the Conflation of Empirical Assessments and Legal Policy Judgments, 7 J. COMPETITION L. \& ECON. 243 (2011), which expands on the concept of a standard reference market and uses it to illuminate problems with market share threshold tests (see infra Section II). See also Louis Kaplow, Market Definition (forthcoming 2013), on all of these subjects, and Louis Kaplow, The Accuracy of Traditional Market Power Analysis and a Direct Adjustment Alternative, 95 HARV. L. REV. 1817 (1982) [hereinafter Kaplow, Traditional Market Power Analysis], for preliminary criticisms, many of which are superseded by my subsequent writing. To avoid clutter, I generally will not refer to these articles for each of the points made herein, leaving it to the reader to locate the relevant discussions, guided by the general content descriptions in this note.
} 
To reiterate, these are propositions of logic, not just practical tendencies. Wishful thinking, felt necessity, and other forces cannot repeal the laws of logic, hard as we might try.

This essay will elaborate these and other themes of my recent writing on market definition, market shares, and market power, intertwining responses to some of the main questions and criticisms that have been raised. ${ }^{2}$ Because the reactions to my work include many points, some addressed specifically in my prior writings, some not directly relevant to specific claims that I advance, and some that time and space do not permit detailed treatment, I will focus here on the core questions, with apologies for not directly addressing each of the many specifics in the papers in this symposium and that have been written elsewhere.

Section I presents the two points described in this introduction and elaborates how they are entirely undisturbed by any of the criticisms that have been advanced. This Section includes responses to central reservations about rejecting the market definition approach and an assessment of how the analysis undermines the hypothetical monopolist test in modern merger guidelines, both as a general matter of logic and as applied in each of the three standard merger settings. Section II describes a related set of propositions concerning the use of market share thresholds in competition law and the difficulty of communicating about market power in the language of market shares. Section III discusses the excessive focus on cross-elasticities rather than elasticities, a problem not inherent in the market definition approach but one encouraged by it.

\section{MARKET DEFINITION LOGIC}

\section{A. Market power inferences from market shares in redefined markets}

Let us begin with the first question: How can one turn lead into gold? That is, how can one make legitimate market power inferences from market shares, supposing that one has chosen the so-called relevant market as best one can? This challenge, along with the next, immediately confronts the problem that the concept of a relevant market does not exist in industrial organization economics. ${ }^{3}$ This point should give one great

\footnotetext{
${ }^{2}$ These include three of the pieces in this symposium-Duncan Cameron, Mark Glick \& David Mangum, Good Riddance to Market Definition?, 57 AnTITRUst Bull. xxx (2012); Malcolm B. Coate \& Joseph J. Simons, In Defense of Market Definition, 57 ANTITRUST BuLL. xxx (2012); Richard S. Markovits, Why One Should Never Define Markets or Use Market-Oriented Approaches to Analyze the Legality of Business Conduct Under U.S. Antitrust Law, 57 ANTITRUST BuLL. xxx (2012) —and another recent paper, Gregory J. Werden, Why (Ever) Define Markets? An Answer to Professor Kaplow, SSRN (February 13, 2012). Note, however, that Coate and Simons's essay is much more a critique of a set of papers (which they most associate with Joseph Farrell, Michael Katz, and Carl Shapiro) on particular techniques for dealing with differentiated products mergers, with little more than a tenth directed at my writing on market definition more generally. Also in this symposium is Herbert Hovenkamp, Markets in Merger Analysis, 57 ANTITRUST BULL. Xxx (2012), who addresses my work only in passing, indicating agreement in instances where it is mentioned.

${ }^{3}$ See, e.g., Franklin M. Fisher, Economic Analysis and “Bright-line” Tests, 4 J. COMPETITION L. \& ECON. 129, 132 (2008); Franklin M. Fisher, Horizontal Mergers: Triage and Treatment, 1(2) J. ECON. PERSP. 23, 27 (1987); Louis Kaplow \& Carl Shapiro, Antitrust, in 2 HANDBOOK OF LAW AND ECONOMICS
} 
pause, especially since many of the leading economists in the field, for over half a century, have studied competition law and policy, served in government agencies, and testified as experts in disputes about market definition and market power.

Economics does have something to say about the question of how one might go about inferring market power from a firm's or group of firms' market shares. For homogeneous goods markets, there exist formulas in certain models that make this possible. There are two standard models, one for a dominant firm facing a competitive group of fringe firms, which will be stated here, and another for multiple firms engaged in so-called quantity competition, which will be discussed in Subsection D.

As documented in my prior writing (and which I had thought was not controversial), the central purpose of the market definition / redefinition process in competition law is to make inferences about market power-and, in any event, that is the purpose to which my work is addressed. ${ }^{4}$ Market power, in turn, is defined as the degree to which price $(P)$ may profitably be elevated above a competitive level, which is where price equals marginal cost $(M C) .^{5}$

This concept of market power plainly makes no reference to relevant markets or market shares. The journey from a definition of market power that is based on the relationship of price to marginal cost to a consideration of market definition and market share is motivated by the practical difficulty of applying the definition directly. In

1073, 1091 (A. Mitchell Polinsky \& Steven Shavell eds., 2007); Adriaan ten Kate \& Gunnar Niels, The Relevant Market: A Concept Still in Search of a Definition, J. COMPETITION L. \& ECON. 297, 298 (2009). In this light, it is odd that Cameron, Glick \& Mangum, supra note 2, at $\{4\}$, can purport to describe economists' conceptualization of the relevant market. It may be true, as they state, that "most economists today adopt some version of the formulation" in the U.S. Merger Guidelines, but "adopt" needs to be understood as acceptance when operating in the antitrust realm, not when doing industrial organization economics per se.

${ }^{4}$ I am skeptical that market definition is useful for other purposes that have been suggested. Most notably, some seem to think it can help make interim decisions about data collection or other matters that might serve as inputs to making market power inferences. See, e.g., Werden, supra note 2, at $\{12\}$; cf. Cameron, Glick \& Mangum, supra note 2, at \{3-4, 24\} (arguing that market definition helps to organize the analysis of constraints on market power, ignoring that one must measure those constraints as a prerequisite to defining the market). However, as Subsection B explains, since one must already have one's best estimate of market power to choose the best market definition, this process seems just to add an intermediate step in an impossible process. For those advancing this or other uses of market definition, it is necessary to state precisely what the purpose is and then to indicate, in light of that purpose, just what is the criterion by which one deems one market definition to be superior to another. Writers seem most reluctant to take even these preliminary steps. See also Werden, supra note 2, at $\{3-5\}$ (asserting with little explanation that "[m]arket delineation remains essential" because we sometimes need to assess entry, and also to identify the "metaphoric arena" of competition). Werden also endorses the traditional market definition paradigm because it provides a useful "narrative" for presenting or defending an antitrust case. Id. at $\{14-17\}$. I will leave it to the reader whether a narrative-which is embraced not as a metaphor but as a paradigm for decision-making, when in fact the approach is logically bankrupt - is the best way to continue talking about market power. Furthermore, do we really want to spend huge sums having experts testify and be rebutted at length on the proper market definition solely for purposes of a judge deciding which lawyer's rhetoric is more apt?

${ }^{5}$ Coate \& Simons, supra note 2, at $\{5 \mathrm{n} .7\}$, seem implicitly to criticize me for not recognizing other views, but I actually assessed these in a section of my 2010 article. See Kaplow, Why (Ever) Define Markets?, supra note 1, at 498-502. 
particular, measuring market power straightaway requires assessing marginal cost, which often is difficult in light of the need to allocate joint costs and to determine which costs are fixed versus variable in the pertinent time frame. Still, the difficulty of measuring a parameter does not ordinarily lead economists (or chemists, or anyone else) to measure something altogether different.

The link, as already suggested, requires models in which one can derive a relationship between market share and market power. In the dominant firm model with a competitive fringe, a standard implementation of the definition of market power, the Lerner Index $(L)$, is in this case determined by the formula: ${ }^{6}$

$$
L=\frac{P-M C}{P}=\frac{1}{\left|\varepsilon_{f}\right|}=\frac{S}{\left|\varepsilon_{d}\right|+(1-S) \varepsilon_{r}} .
$$

In this formula, the firm's elasticity of demand is $\varepsilon_{f}=(d Q / d P)(P / Q)$, where $Q$ denotes the quantity of the firm's output; the market elasticity of demand is $\varepsilon_{d}=(d X / d P)(P / X)$, where $X$ denotes total market demand; and the rivals' collective elasticity of supply is $\varepsilon_{r}=$ $(d Y / d P)(P / Y)$, where $Y$ denotes rivals' total supply. Finally, $S$ is the dominant firm's market share, and hence $1-S$ indicates rivals' aggregate share.

The first equality defines the Lerner index: the fraction of the price that is in excess of marginal cost. The next is derived from the dominant firm's profit-maximizing calculus: a higher price raises profits on retained sales but sacrifices profits on forgone sales. The optimal elevation is given by the inverse of the firm's elasticity of demand, which indicates the rate at which the firm loses sales in all forms. The final equality decomposes the firm's demand elasticity into the sum of the market elasticity and fringe firms' supply elasticity, the latter weighted by their share. This summation reflects that sales may be lost to other products or to other suppliers of the same product. The intuitive relevance of market share to market power can be seen in this rightmost term: the $S$ in the numerator is due to the fact that a given price increase (caused by a quantity reduction) is profitable to the dominant firm in proportion to its share of industry sales, and the $1-S$ in the denominator indicates that a higher dominant firm share makes the rivals' share lower and hence reduces the impact of a given supply response (the elasticity measuring that response in percentage terms).

Using the dominant firm's share in the homogeneous products market, we can therefore determine its market power if we can ascertain the market elasticity of demand and the fringe's elasticity of supply (or, with some techniques, we might instead measure the firm's demand elasticity directly). It should be emphasized that this is so regardless of how many substitutes exist for the firm's product or how strong those substitutes are. ${ }^{7}$ In other words, this formula gives us the answer we seek without having to undertake any of the standard market definition analysis. (This statement, in terms of product market definition, has analogues for geographic market definition, which might be viewed as pertaining to the rivals' supply response.)

${ }^{6}$ See George J. Stigler, Notes on the Theory of Duopoly, 48 J. POL. ECON. 521, 523-24 (1940); William M. Landes \& Richard A. Posner, Market Power in Antitrust Cases, 94 HARV. L. REV. 937, 944-47 (1981); Kaplow \& Shapiro, supra note 3, at 1080-81.

${ }^{7}$ See infra Section III (elaborating the relationship between the elasticity of market demand and cross-elasticities for individual products). 
Having concluded that market redefinition is unnecessary, suppose now that we do it anyway. That is, suppose that there are some substitutes deemed to be sufficiently close that we should broaden the market to include them. If this step is undertaken, we then need a formula - a new formula - to infer market power in this now-heterogeneous goods market.

At this point, we have entered the land of alchemy, and only those like Gul can continue. The simple reason is that there is no such formula. ${ }^{8}$ The formula presented above is valid only for markets with homogeneous goods. It has long been supposedhere is where imagination and wishful thinking have played a great role, including for this author once upon a time- - that perhaps one could apply an analogue to that formula for the broadened market, making suitable interpretations of the elasticities in the rightmost expression - the market share being fairly straightforward, and lower, supposing that the dominant firm does not also produce the now-included substitute products. $^{9}$

The problem is that these common suggestions amount to little more than handwaiving. For the reinterpreted elasticities to be grounded, there needs to be a model that generates a formula that enables us to perform the necessary translation. As shown in my prior article, there exists a unique way to reinterpret these elasticities, which involves scaling them down to precisely offset the effects of the lower $S$ in the formula. Put more bluntly, the only correct method involves undoing the market redefinition. ${ }^{10}$ This can be

\footnotetext{
${ }^{8}$ Cameron, Glick \& Mangum, supra note 2, at $\{2\}$ (emphasis added), misleadingly summarize this logical attack as follows: "Professor Kaplow claims that because market definition does not produce a strict correspondence between a firm's market share and the value of that firm's Lerner Index, it has no value." See also id. at $\{13,19\}$.

${ }^{9}$ This strategy is pursued in Landes \& Posner, supra note 6, with criticisms advanced, for example, in Richard Schmalensee, Another Look at Market Power, 95 HARV. L. REV. 1789 (1982), and Kaplow, Traditional Market Power Analysis, supra note 1. Strangely, Coate \& Simons, supra note 2, at $\{3\}$ (emphasis added), seem to believe that my critique "serves to echo the Landes-Posner observation that case-specific competitive analysis must be undertaken to interpret the share data associated with any market definition.” Later, id. at $\{21-22\}$, they assert that the problem I raise somehow is not a problem, as if a raw assertion can provide an answer that I demonstrated cannot exist. At one point, they note that "to the extent that the elasticities associated with the composite goods market are easier to recover from the facts than the elasticities associated with the more homogeneous good market, the broader market (the 'redefined market') would be preferred to the initial narrow market." Id. at $\{22\}$. But this totally misses the point that there is no such thing — at least in any relevant sense-as the "elasticities associated with the composite goods market," and they do not attempt to define this concept. Moreover, this problem was emphasized in Schmalensee's critique (which I cited and discussed in some detail in my original article), where further, more rigorous analysis was provided, which Coate and Simons ignore as well. Moving from the strange and incomplete to the bizarre, they state in a footnote, $i d$. at $\{22 \mathrm{n} .66\}$, that "Kaplow's equations 5 and 6 do not need to hold in equilibrium when the prices of all the products in the new broader market are allowed to change." What! How is it that an analyst's choice to use one metaphor rather than another causes actual prices in real markets to change? (The reader might also note that the two equations they reference are the ones involving the hypothesized elasticities in the redefined market, which elasticities I conclude are meaningless, unless one undoes the market redefinition.)
}

${ }^{10}$ Cameron, Glick \& Mangum, supra note 2, at $\{27-28\}$, purport in a brief Appendix to offer a formula that works for a special case, but what they present is impenetrable (for example, some variables are not defined, they take a derivative but do not say with respect to what, they seem to have a singlevalued demand function for differentiated products, they appear to implicitly assume a single price for all the products-all of which may be a misunderstanding, but much too much is unspecified). The problem 
seen, for example, by taking a case in which the rivals' supply elasticity is zero. In that event, if the redefinition reduces the share, say, by $72 \%$, one would simply deem the market elasticity of demand in the combined market to be $72 \%$ less than that in the original, homogeneous goods market. Obviously, this fudge factor gives us the correct answer, and any other adjustment will not. But if this method is the only valid way to interpret elasticities in the combined market, there obviously is no point to ever redefining markets. ${ }^{11}$

\section{B. Choosing the best market}

Let us now, for purposes of this Subsection, wave our magic wand (like we have been for over half a century) and pretend that lead can be made from gold, i.e., that there is some way, albeit imperfect, of making valid market power inferences in redefined markets. ${ }^{12}$ We now turn to our second challenge, making lead. Now, in reality, lead is not that hard to come by, which is why the Introduction's supposition to the contrary required some license. But for the relevant market, we truly do need to make something from nothing. As already mentioned, the concept does not even exist in industrial organization economics. Is there a way to remedy the gap — to invent a new process?

In confronting this question in my writing on the subject, I begin by positing a criterion. If we are going to choose between two markets, call them Narrow and Broad, and say that one of them is better-or, when there are myriad possibilities, as there generally are, best — we cannot be saying anything coherent until we have a common understanding of what is meant by best. Prior literature, agency pronouncements, and court opinions are remarkably silent on this matter. ${ }^{13}$ Because the whole point of

they purport to address was a focus of Schmalensee, supra note 9, who, like me, comes to a different conclusion. (Note further that my argument was not that the problem was impossible, but rather that the uniquely correct answer entails, at least implicitly, fully undoing the market redefinition.)

\footnotetext{
${ }^{11}$ Note that the proper degree of scaling down has nothing to do with the elasticity of demand for the goods added to the market.

${ }^{12}$ Werden, supra note 2, at $\{5-9\}$, mistakenly associates the analysis of the dominant firm model with the present argument, to which it is entirely unrelated. As do Cameron, Glick \& Mangum, supra note 2 , at $\{10-11,19-20\}$. I am surprised by these misreadings in light of the facts that my original article presents them in separate (nonconsecutive) Parts, begins the latter (what is here Subsection I.B) by explicitly setting the former (I.A) to the side (see Kaplow, Why (Ever) Define Markets?, supra note 1, at 469), and at no point makes use of the dominant firm formula or anything like it. It should be apparent to present readers that the logic in this Subsection (I.B) is independent of the specifics of the preceding one (indeed, one must set the preceding problem to the side for the market definition approach even to have meaning for present purposes).
}

\footnotetext{
${ }^{13}$ As are the responses cited in note 2. To illustrate, Cameron, Glick \& Mangum, supra note 2, at $\{12-13\}$, state that I "ask[] the wrong question and therefore reach[] the wrong conclusion." The question under consideration is "what market definition is best." In the part of my prior article that they are addressing, I am insisting that one must invoke a criterion, and I offer the one that we seek the best inference of market power. Do these authors want an inferior answer to that question? An answer to a different question? What question? And what is their criterion? And how would one define a market under it? Coate \& Simons, supra note 2, at \{24-26\}, seem to believe that market definition remains useful despite the lack of any criterion whatsoever. Yet in so arguing, they refer to analyses being "easier if
} 
choosing a relevant market is to be able to use the resulting market share therein to make as accurate a market power inference as possible, the most sensible criterion holds that the best market is the one that leads us to make the most accurate market power inference.

It is understood that the inference process is imperfect. Notably, in our current illustration, suppose that, should we choose Narrow, we will overstate market power by some amount, whereas if we instead choose Broad, we will understate market power to some degree. We seek the lesser of two evils. That is, the best choice is that which results in the smaller error, as best we can determine using the information at hand.

A necessary condition to define a market, therefore, is a measure of the expected error from each choice. Now, what is the error associated with selecting some given market as the relevant market? It is the difference between the degree of market power we would infer, conditional on that choice, and our best estimate of market power.

It follows immediately that there is no way to estimate-or guesstimate- the magnitude of any error without first estimating — or guesstimating-market power. This point, note, is purely a matter of logic, really of definitions. Error means the difference between the market power we will infer under a given market definition and actual market power, as best we can estimate it. ${ }^{14}$

At this point, we have a catch-22: A necessary input in the process of market definition is our best estimate of market power, but the whole point of the market definition exercise was to enable an inference about market power. That is, we want lead in order to make gold, but the only way to get lead is to use gold as an input. ${ }^{15}$

undertaken within the confines of a well-defined relevant market.” How one defines something well with no criterion and no workable method is left to the reader's imagination.

\footnotetext{
${ }^{14}$ Werden, supra note 2, at $\{7-9\}$, offers examples that purport to define markets without explaining how this problem is avoided. In his first two examples, he chooses the narrow market when the elasticity is "low" and the broad market when it is "high." But this is a blatant evasion. How low is "low," and how high is "high"? By what criterion is this determined? Obviously if "low" means "low enough that choosing the narrow market is better than choosing the broad market, in that it leads to a better market power inference," and if "high" means "high enough that ....," then his examples run directly into the core problem I raise. So "low" and "high" must mean something else. But what could that be? And why would we care about it? No hint is offered. Werden also never mentions what one would do with these market definitions in light of the fact that there exists no way to make market power inferences from the resulting shares (except in the homogeneous goods market, which involves no redefinition). (Werden's last two examples refer to how some methods he attributes to me, without citation or elaboration, would provide poor assessments in certain situations. Unfortunately, I could not tell what he is talking about. Relatedly, Werden, $i d$. at $\{19\}$, criticizes me for not offering a concrete method for addressing a particular, somewhat complex case, which is rather odd since I do not affirmatively offer specific methods for addressing any case, my articles being conceptual. What I do argue is that market (re)definition can never help, and Werden does not show how market definition could be conducted or how it could help in the example in question, although he nevertheless asserts that somehow it can be done and would be of assistance.)

${ }^{15}$ Coate \& Simons, supra note 2, at $\{23\}$, assert that "Kaplow’s aggressive attack on the market definition concept flounders on the need to create a benchmark for significant 'monopoly' power prior to the definition of the correct market." As the reader can plainly see, this supposed criticism has nothing to do with what I am arguing. (More broadly, how could the choice of a legal threshold for monopoly power bear on the logically distinct question—see infra Section II—of what techniques are helpful in measuring power?)
} 
A moment's reflection reveals that the problem is actually worse, as suggested in the Introduction. When we use the gold as an input, however impure it might be, to make lead-which is then converted back into gold - it leaves us with a more impure product than that with which we began.

To see this, suppose that we have determined, using our best estimate of market power, that the best market is Narrow. Now, we have already said that we know that, when we deem Narrow to be the relevant market, we will overstate market power. Specifically, the resulting market power inference is higher than our best estimate of market power. That, after all, was the error that we were measuring. Of course, we could have done worse: if we chose Broad, our error, by supposition, would have been greater. We have the lesser of two evils.

But why go with the lesser of the two evils when this is entirely unnecessary? One can instead just stick with the best estimate of market power that we referenced when choosing Narrow as best. Quit while you are ahead!

Moreover, it should be apparent that this avoidable error in market power inference will sometimes lead us astray. In cases in which Narrow is best and the resulting market power inference just crosses our threshold (say, for condemning a merger), we will have made a mistake because our best estimate in these circumstances is below the threshold. Granted, our best estimate is only an estimate. But it is, by definition, our best estimate. Using something we know to be worse to reach a different, inferior outcome is not merely pointless, but perverse.

The same is true when Broad turns out to be the best market definition, again, the lesser of two evils. We know that we are then understating market power, relative to our best estimate, so we will sometimes be too lax, exonerating acts that our best estimate indicates should be condemned. Also perverse.

\section{Some lessons}

Subsections A and B make two basic, logical points. ${ }^{16}$ The choice for the competition law and policy community is whether to heed the inescapable implications or to continue to pretend that we inhabit a universe in which alchemy works.

In the years that I have been working on my recent articles on this subject, circulating drafts, making presentations, and reading reactions (including those in this symposium), I have encountered substantial resistance, which seems to me best understood as a form of denial. In this Subsection, a number of these complaints are recounted.

\footnotetext{
${ }^{16}$ Coate \& Simons, supra note 2 , at $\{52\}$, in their conclusion, complain about my criticisms of market definition not being backed up “with empirical evidence.” However, as emphasized since the Introduction, these two core critiques (and, as we will see, those in later sections as well) are matters of pure logic. Perhaps Coate and Simons might offer counterexamples, illustrating the actual conversion of lead into gold? Relatedly, they continue by stating that my "approach would replace standard market definition analysis with an economic theory that is not well substantiated.” $I d$. at $\{53\}$. It is the market definition approach that is unsubstantiated; indeed, as mentioned, in the economic theory of industrial organization it does not even exist. This objection is related to the first two emphasized points that follow in this Subsection.
} 
- Measuring market power directly is hard, often very hard, so don't we at least sometimes need to use the market (re)definition approach ? $^{17}$

It should now be obvious that this is a non sequitur. When something is hard to do, we do not substitute a method that is literally impossible. Gold is hard to come by, so alchemy is appealing. But if it is impossible to turn lead into gold, and furthermore the only way to fabricate lead requires using gold that is less impure that any the alchemists even claim is possible to produce from the lead, it is time to abandon alchemy and get about the business of doing the hard work - in our case, of estimating market power as best we can.

Whether the best approach in a given setting involves application of some econometric technique, consulting sophisticated buyers, scrutinizing firms' internal records, or, when in a hurry, simple introspection —or, often, a combination of methods-is a matter of economic judgment that is beyond the scope of this present series of articles. But since, as per Subsection B, we do need a best estimate of market power as an input to defining markets, there is no getting around this.

- In the case at hand, a particular, favored technique of assessing market power directly is hopeless, so shouldn't we use market definition instead?

The same non sequitur. If a particular way of obtaining gold is unavailable, the leadbased approach is still impossible, and it still presumes that we already have gold (of higher purity) even if we believed the conversion could work.

- Shouldn't we use market definition to screen cases quickly since it is a lot easier to do than direct estimation? ${ }^{18}$

This cannot be so, as should by now be clear. But why does this particular reaction seem so alluring? The answer lies not in the magic of market definition but instead in the fact that easy cases are easy. Consider the typical application of this notion. We want to quickly screen out the large number of possible cases (perhaps merger applications) that do not plausibly pose any serious risk. Often, we see two firms merging and it is just obvious that the correct market definition is a broad one, and, moreover, even if that may result in some understatement of market power, the case is not at all close: the firms' combined share in the broader market is tiny, so it seems certain that, whatever the increment to market power might be, it is negligible.

\footnotetext{
${ }^{17}$ The core of the criticisms in Coate \& Simon, supra note 2, that are levied at my writing fall somewhere between this objection and the next. For example, in their introduction, id. at $\{2-3\}$, they present as the two main problems that there are certain limitations to particular models, which then is said to render market definition a useful tool. See also, e.g., id. at $\{24\}$ (arguing that the existence of long-run cost considerations makes it difficult to determine a threshold value of the Lerner Index, which somehow interferes with the ability to choose a best market definition, which in turn implicitly seems to justify using a method that has been shown to be inferior); supra note 16 (noting their concluding remarks).

${ }^{18}$ See, e.g., Cameron, Glick \& Mangum, supra note 2, at $\{2,17,19-20\}$.
} 
This idea is logically flawed, but the error is nearly harmless. The most obvious gap is that there was no way to know that the broad market was clearly correct unless we were essentially certain that the narrower market overstated market power by much more than the broad one understated market power. That is, we are supposing that we already know that our best estimate of market power is a very low one, so we are comfortable in choosing the broad market without hesitation. But if we are correct - that is, the market power is indeed very low-we are, of course, done. By force of habit, our minds perceive the broad market to be correct, but that would only be right if we just as quickly, even if subconsciously, already perceived the market power to be very small. ${ }^{19}$

- $\quad$ The dominant-firm model with homogeneous goods is a very special case, so why should we accept a conclusion from that model $?^{20}$

This source of skepticism misunderstands the use of models being made here. By no means is the model a precise fit on the world, and in many settings it is a terrible fit. The point being made in Subsection A, however, was that we need some basis for inferring market power from the market share in a redefined market-some way of turning lead into gold. It was explained that, under the simple, idealized conditions of the model, this was impossible. Adding further complications cannot help; they would merely suggest that, if we could have found a way to make a legitimate market power inference in the redefined market, that way would have been subject to qualifications, possibly large ones. But since it turned out that, even under the most favorable circumstances, we could not make a legitimate inference, we never reached the point of having to consider whether the process may work less well, or not at all, under more challenging conditions. (Note also that this query is inapplicable to the second point, that one needs gold to make the lead in the first place.)

\section{- But doesn't existing law require market definition?}

My writing does not, for the most part, address the requirements of existing law. However, it does offer some observations worth keeping in mind. First, especially in the United States, both statutes and cases seem far more open than many commentators, lawyers, and judges seem to appreciate. For example, market definition is explicitly regarded as a means to an end, that end is taken to be making market power inferences, other means of making such inferences have been endorsed, and it has long been

\footnotetext{
${ }^{19}$ The only risk is that, by skipping the central step and keeping the underlying basis for our decision implicit, we might sometimes overlook a potential for error. For example, as some suggest and the court believed in Staples, a counterintuitively narrow product market may sometimes be best. And in some other cases - think electricity generation and oil refining_rivals' supply may be extremely inelastic, so small shares may convey nontrivial market power.

${ }^{20}$ See, e.g., Cameron, Glick \& Mangum, supra note 2, at $\{2\}$ ("Professor Kaplow underestimates the limitations of the theoretical relationship between market share and market power that can be derived from the Dominant Firm model.”); id. at $\{15-17\}$ ("It would be a serious mistake to assume that any of these models are complete enough to define a sufficiently exact relationship between market shares and price-cost margins to attain Professor Kaplow’s purported goal ....”).
} 
recognized that any inferences from market shares must be made cautiously and potentially revised or rejected in light of other evidence. $^{21}$

Second, if directly confronted with the matter, would twenty-first century courts really embrace alchemy? That is, once it becomes well accepted that the market definition approach is illogical and cannot be resurrected, would decision-makers really insist on its continued use? And, by the way, what are economist experts really saying when they proffer opinions on market definition, in light of the fact that the concept does not exist in the pertinent field of economics and given the above logical attacks that go to the very core of the method?

Third, if one insists on market definition, one can satisfy such a formal doctrinal requirement by working backwards — which it appears courts and enforcement agencies already sometimes do (e.g., in the Staples opinion). ${ }^{22}$ That is, one first examines all evidence pertinent to market power, then makes the best estimate possible, and uses that estimate to reach the correct legal conclusion. But, before writing that down at the end of an opinion, one inserts an intermediate market definition conclusion, choosing the relevant market using post hoc rationalization: that market which ratifies the legal conclusion reached on other grounds. Here, the market definition is a pure appendage, serving no independent analytical function. Although this method is circular, it does have the important virtue of enabling a decision-maker to reach the best legal outcome, a trait that the standard approach lacks.

\section{The merger guidelines' hypothetical monopolist test}

For three decades, the competition law and policy community has become familiar with and routinely deployed the hypothetical monopolist test (HMT) from the merger guidelines. ${ }^{23}$ The basic approach is to begin with the narrow, homogeneous goods market and ask whether a hypothetical monopolist in that market could profitably impose a "small but significant and non-transitory increase in price ('SSNIP')," say five percent. ${ }^{24}$ If yes, that is the relevant market. If no, one adds the next layer of substitutes (a concept that is not well defined) and repeats the test, continuing until it is passed. Then, merger guidelines make various inferences from the market shares in that market. For example, the 2010 U.S. Merger Guidelines state: "Mergers resulting in highly concentrated markets [with an HHI above 2500] that involve an increase in the HHI of more than 200 points will be presumed to be likely to enhance market power." ${ }^{25}$

\footnotetext{
${ }^{21}$ For additional supportive suggestions, see Hovenkamp, supra note 2, at $\{1-11\}$.

${ }^{22}$ FTC v. Staples, Inc., 970 F. Supp. 1066 (D.D.C. 1997).

${ }^{23}$ See, e.g., U.S. DeP’T OF Justice \& Fed. Trade Comm’n, Horizontal MERGER Guidelines (2010) [hereinafter U.S. MERGER GuIDELINES]; Guidelines on the Assessment of Horizontal Mergers Under the Council Regulation on the Control of Concentrations Between Undertakings, 2004 O.J. (C 31) 5; Commission Notice on the Definition of Relevant Market for Purposes of Community Competition Law, 1997 O.J. (C 372); DG Competition Discussion Paper on the Application of Article 82 of the Treaty to Exclusionary Abuses (Dec. 2005).

${ }^{24}$ U.S. MERGER GUIDELINES, supra note 23, §4.1.1.

${ }^{25} I d . \S 5.3$.
} 
Unfortunately, lead is still lead. Promulgating a new test cannot repeal the laws of logic. Consider each of the two foregoing critiques. ${ }^{26}$

First, lead cannot be turned into gold. Once one has used the HMT to define a relevant market, how are market power inferences to be made from the shares therein? Well, the Guidelines take shares (in the form of HHIs) and associate conclusions with them. But where do those conclusions come from? After thirty years (since the 1982 U.S. Merger Guidelines), we still do not know. Indeed (see Section II), the Guidelines never tell us how market power they are looking for in deciding whether to challenge a merger. In sum, there is no real market power inference that is stated; instead, we jump straight to conclusions about challenges, safe harbors, and so forth. But, then, how could it be otherwise? The price elevation associated with given shares could be very high or quite low. As Subsection A demonstrates, once one begins redefining markets, there is no way to make valid market power inferences from the shares therein (short of undoing the redefinition and going back to the homogeneous goods market, on which more in a moment).

Second, we need gold to make lead. How do the Guidelines manage to define a market without using a best estimate of market power, which Subsection B indicates is logically necessary? Having not repealed the laws of logic, we can see, on reflection, that there are two key sources of slippage in the HMT. One is that it does not even purport to choose the best market. Those reading the Guidelines and using various versions for

\footnotetext{
${ }^{26}$ Remarkably, Werden devotes an entire section of his essay to merger analysis and cites the HMT as a solution to many problems, yet makes little mention of many of the critiques, general and specific, reviewed here, including my numerical example (which appears previously). At one point, Werden, supra note 2, at $\{12-13\}$ (emphasis added), refers to the "setting of undifferentiated industrial commodities," indicating that my analysis of that case performs poorly "[i]f the merging firms produce different goods," but I could not infer from this pairing what argument, if any, of mine he meant to address. He also at one point refers to the need for "something akin to market delineation" in a certain setting. Id. at $\{12\}$. But I have no idea what that is, how it would be conducted, how it would avoid my critiques, or what purpose it is supposed to serve.

I also find it strange that Coate \& Simons, supra note 2, at $\{23$ n.69\} scold me for not "fully" discussing the HMT in my original article-which was already quite long. The page they refer to (Kaplow 2010, at 466) contains, among other things, the following passage:

Some might regard the hypothetical monopolist SSNIP test employed in the U.S. Merger Guidelines and followed in other jurisdictions to be an exception. However, as will be discussed below, this test constitutes a mechanism, not a pertinent criterion; it generates a determinate market definition outcome that is not directly addressed to how much market power is increased by the merger under consideration, which is to say the merger's likely effect on price. Its method is also subject to the central criticism developed in this Part.

Later discussion in my article includes the three main scenarios examined here as well as a detailed numerical example. Coate and Simons themselves rely heavily on the HMT approach, which they see as having broad acceptance (id. at $\{12\}$ ), while not responding directly to any of my critiques, either the general ones applicable to any approach to market definition or the particulars regarding the HMT. They kindly mention my other paper that focuses on the Merger Guidelines and the HMT, but largely ignore its content as well. They assert that my discussion there "centers" on hypothetical examples, which refers to a page or so of the entire article. Moreover, as explained in the text below, my point was that the HMT fails miserably even in the simplest and purest case that it was designed to address. It is as if adding complications would somehow rescue the approach, for reasons that are not offered. This point is pretty damning for Coate and Simons's essay (which, as mentioned in note 2, is not largely focused on my writing) because they insist throughout that the market definition approach, as embodied in the HMT, should continue to be employed prominently.
} 
decades might be surprised to learn this. But, when one looks at the Guidelines and the surrounding commentary over the years, one does not see any actual criterion being articulated. That is, the HMT is an algorithm that answers a question, but the question has never been stated. And we now know that the question the HMT actually answers can not be: What is the best market definition, where best is understood as providing the most accurate market power inference?

Another way to assess the approach of the Merger Guidelines is to consider their application in the three main settings that they address: unilateral price elevation in homogeneous goods markets, unilateral elevation in differentiated products markets, and coordinated elevation. ${ }^{27}$ When we examine each in turn, we can see that the HMT is never a useful approach, providing further confirmation of the more general, abstract criticisms already levied.

Unilateral effects: homogeneous goods.- The bottom line in this case is that the best way to estimate price elevation is to stick with the homogeneous goods market, and as we shall see reliance instead on the HMT can lead us badly astray. This case is considered first because it is most like that involving the dominant firm and competitive fringe that we examined in Subsection A. Indeed, this case presents the other main instance in which economists have derived a formula relating market shares to market power, so it helps round out the preceding discussion.

The particular scenario is the Cournot quantity-competition model with homogeneous goods. The formula indicates that the industry-wide average, outputweighted margin equals $\mathrm{HHI} /\left|\varepsilon_{d}\right|$ (where the $\mathrm{HHI}$ is represented in ten-thousandths, so that its range is from 0 to 1$).^{28}$ Now, if we really have Cournot quantity competition, ${ }^{29}$ this formula tells us that we can compute the price elevation as a function of the market shares (the HHI). However, just as in Subsection A, our formula is applicable only in the initial, homogeneous goods industry. That is, if we stick with the original, homogeneous goods market, we can compute our price elevation: specifically, we can compare the elevation using the pre- and post-merger HHIs. But if we instead follow the HMT when

\footnotetext{
${ }^{27}$ Werden, supra note 2 , at $\{13\}$, asserts that I "wrongly presume[] that just two simple models reflect the full range of competitive settings in which unilateral effects concerns arise.” Hardly. What I do is refer to the two core unilateral effects settings that are the focus of the U.S. Merger Guidelines and the vast majority of writing on the subject. Then, in those cases, I show that the favored approach fails. These demonstrations are offered as concrete illustrations of my more general critique that the market definition paradigm is useless as a matter of logic for two reasons. None of this implies that there are not mixed cases or other variants of interest. But if a technique is utterly useless and in fact counterproductive in the core cases for which it was devised, it takes powerful wishful thinking to imagine that, when complexities are added, it will recreate itself, overcoming inherent logical defects. Not surprisingly, Werden does not even attempt to describe how this alchemy is possible.

${ }^{28}$ See, e.g., Janusz A. Ordover, Alan O. Sykes \& Robert D. Willig, Herfindahl Concentration, Rivalry, and Mergers, 95 HARV. L. REV. 1857, 1865 (1982); Kaplow \& Shapiro, supra note 3, at 1085. I will ignore the important qualifications in Joseph Farrell \& Carl Shapiro, Horizontal Mergers: An Equilibrium Analysis, 80 AM. ECON. REV. 107 (1990), because they are not pertinent for present purposes.

${ }^{29}$ See the objection in Subsection C (regarding models' use of simplifying assumptions) if we do not. In short, we would need to amend the analysis to take account of further complications, but such could not resurrect a ground for using the HMT that never existed in the first place.
} 
it tells us to redefine (broaden) the market, our formula is void and there is no other formula to replace it. Hence, the standard merger guidelines method is the wrong one in this setting -interestingly, the one setting in which we have a formula that uses market shares, and, specifically in terms of the HHIs used in the guidelines. That is, the Guidelines take a case in which an economic tool exists, discards it, and substitutes an alternative approach that has no grounding and cannot be supported as a logical matter.

Nor is this criticism purely academic. It is also true that the standard method does a poor job even of generating a consistent ordering of possible mergers: that is, whether or not a challenge is appropriate under the Guidelines using the HMT is quite poorly correlated with actual predicted price elevations. To see this, consider under the U.S. Guidelines a merger in which the 5\% HMT is barely satisfied for the homogeneous goods market. Suppose further that the merger raises the HHI from 2300 to 2501, in which case it is deemed presumptively to pose a threat, as mentioned above. The pre-merger elevation would roughly equal 0.23 (from the HHI of 2300) divided by the market elasticity of demand, whereas a hypothetical monopolist, which we have supposed can raise price $5 \%$ over the prevailing level, has a Lerner Index equal to 1.0 divided by that elasticity. One can calculate that these relationships are consistent with an elasticity of approximately 15 , a pre-merger elevation of about $1.49 \%$, and a post-merger elevation of approximately $1.62 \%$. Therefore, the merger-induced elevation is about $0.13 \%$, that is, under two tenths of one percent.

By contrast, if the hypothetical monopolist in the homogeneous goods market can only raise price $4.9 \%$, we are instructed to expand the market. Now, if the first set of substitutes that we accordingly include involves far more revenue than does the original market, then even a merger to monopoly in the original homogeneous goods market would not trigger scrutiny. But we had just stipulated that such a merger would raise price $4.9 \%$.

Let us now combine these two results: the Guidelines method would presumptively condemn the first merger, which raises price by $0.13 \%$, and exonerate the second, which raises price by $4.9 \%$, which is to say, over thirty-five times more than does the first merger. This example provides two lessons. First, the HMT is a poor means of attempting to assess the price effects of mergers. Other considerations, such as entry or efficiencies, may alter the outcomes. But to see if the test fundamentally makes sense, it is appropriate to consider a basic case in which such factors are held constant-even better, for simplicity, are of no importance — and then to ask whether the Guidelines' HMT works at all well in even the simplest setting, where no complications are present. Unfortunately, it does not.

Second, various merger guidelines' use of HHI criteria foreshadow the point to be developed in Section II that it is a mistake to denote market power tests using market share thresholds. This mismatch helps to explain how a given set of HHI ranges can generate such inconsistent outcomes, condemning a merger raising price by $0.13 \%$ while allowing one that raises price by $4.9 \%$. As noted at the outset of this Subsection, merger guidelines provide elaborate discussions of agencies' methodologies in assessing price effects but do not ordinarily indicate what level of price effects would be sufficient to condemn a merger. As a thought experiment, suppose that, in a challenged merger, an agency's experts and the merging parties' experts simultaneously filed reports, and it turned out that both predicted precisely the same price increase—say, $3.1 \%$, or perhaps 
$1.4 \%$, or $0.2 \%$. Who would win in each instance? Merger guidelines are silent. Indeed, if they are followed conscientiously, one might argue that direct conclusions on price effects are not decisive. After all, these guidelines purport to call for a determination of market definition that uses the HMT, followed by an assessment based on HHIs in the market that is thereby selected.

The HMT and the various market share thresholds indeed perform poorly in homogeneous goods industries with quantity competition. But this problem is totally avoidable because the measure needed to apply the first round of the HMT test- the market elasticity of demand for the good in that market - is sufficient to assess directly the effect of the merger on price. Contemplating market redefinition is entirely unnecessary and only leads the analysis astray.

Unilateral effects: differentiated products.-In this particular setting, it has become fairly accepted that market definition is not very useful, as developed in the literature on critical loss analysis and upward pricing pressure. ${ }^{30}$ To assess a merger of

\footnotetext{
${ }^{30}$ See, e.g., Jonathan B. Baker \& Timothy F. Bresnahan, The Gains from Merger or Collusion in Product-differentiated Industries, 33 J. InDUs. ECON. 427 (1985); Barry C. Harris \& Joseph J. Simons, Focusing Market Definition: How Much Substitution Is Necessary?, 12 RES. L. \& ECON. 207 (1989); Daniel P. O’Brien \& Abraham L. Wickelgren, A Critical Analysis of Critical Loss Analysis, 71 ANTITRUST L. J. 161 (2003); Joseph Farrell \& Carl Shapiro, Antitrust Evaluation of Horizontal Mergers: An Economic Alternative to Market Definition, B.E. J. THEORETICAL ECON., Jan. 2010, art. 9, 1.
}

Because Markowits's prior work is a precursor, his analysis focuses on mergers (and differentiated products mergers in particular), and his response piece does not primarily address particulars of my arguments (other than as they relate to his own work), it is convenient to consider his essay as a whole at this point. In my original article, Kaplow, Why (Ever) Define Markets?, supra note 1, at 478-79 n.79, I discussed at some length his most extensive article on the subject, and subsequently have had private exchanges with him regarding his reactions thereto, with only moderate convergence. Among my earlier published statements were that (A) his prior writing constituted a "particularly harsh attack on market definition,” (B) his critique focused on horizontal mergers with differentiated products, in the process anticipating subsequent developments that are now receiving greater attention, and (C) his analysis is hard to interpret (my opinion) and largely differs from mine-where it is clear as well from his current essay that he largely agrees: see, e.g., Markovits, supra note 2, at $\{3\}$ (claiming that his prior articles and mine "focus on different issues"); id. at $\{4\}$ (stating that his arguments are "significantly different from" and also "superior to" mine, the latter being difficult to interpret since they address, in his view, different questions); id. at $\{57\}$ (explaining that "Kaplow and I are discussing different though related issues"). I closed my discussion of that article with a lengthy quotation from his own concluding section that summarizes the main claims there, allowing readers to draw their own conclusions.

His essay in this symposium primarily develops his own ideas that he sees as addressing different questions, although complementary in certain ways to my analysis. I must confess that I have difficulty recognizing any of my main arguments from his part VI (id. at $\{101-05\}$ ) that most directly responds to my 2010 article. Readers are free to make their own comparison. Readers can also form a judgment on his objections to my aforementioned footnote on his 1978 article (part VII, id. at \{105-17\}), which runs about three times the length of his direct substantive critique of my article as a whole. I will offer a few incomplete and unavoidably argumentative observations in this regard. First, Markovits is obviously angry, as a whole and in many specifics, that I did no address all manner of particulars of his argument. Yet, in a footnote running less than a page commenting on a 145-page article, how could this be otherwise? As mentioned, I did quote from his own conclusion summarizing what he presumably regarded as his main points. I also find his annoyance a bit rich in light of the fact that he justifies his failure even to mention in that 145-page article the two leading papers on his subject (two of the authors going on to win Nobel prizes) with the argument that "the approaches they take differ from mine, and I do not think it would have been cost-effective for me to make [my] Article even longer by examining the relationship between my work and theirs.” Id. at $\{113\}$. Likewise, while his current essay cites a large number of his own prior 
two firms that, let us suppose, each produce a single product, we can predict price elevation by knowing the firms' price-cost margins on the two products and the diversion ratio between them. The basic idea is that, after the merger, there is a stronger incentive to raise the price on each good because part of the lost sales are to the other product, which is now controlled by the same entity. Because the cost of raising price is lessened, the motive to raise price is enhanced. ${ }^{31}$

Importantly, determination of the relevant factors - the diversion ratios and the margins on the two products - does not require market definition. ${ }^{32}$ Accordingly, the HMT and the guidelines' various HHI thresholds are beside the point. One could attempt to employ them, but they hardly would provide a reliable guide.

There is one way the problem could be avoided: Apply the first step of the HMT to an initial market with only the two firms' products and no others. And then stop. The first round of the test indicates how much a hypothetical monopolist would raise price. Because under this nonstandard construction our hypothetical "monopolist" consists of the two merged firms and no others, that is our answer. Of course, to apply this variation of the test is to inquire directly into how much the merger will elevate price, precisely the sort of market power inquiry that Subsection B explained to be a necessary input if one wished to choose a best market. Note also that it is important to stop after this first round, regardless of what we learn, contrary to the dictates of the HMT. If one instead expands the market, then the HHIs there, matched against the guidelines' thresholds or otherwise, will not be very useful, in this case illustrating the point of Subsection A that market shares in redefined markets do not provide a valid basis for making market power inferences.

works, it cites none-none-of the subsequent massive literature on the subject of differentiated product mergers, which is the focus of his very lengthy piece. On another matter, he finds "simply false" my suggestion that his analysis “applies only to cases” with individualized pricing, id. at $\{114\}$ (emphasis added), whereas what I actually stated in the clause he finds irksome was that "a large portion of his argument is predicated on firms' pricing individually to consumers," a claim that I stand by and that is reinforced by a notable chunk of his current commentary with regard to elasticities, see id. at $\{108-10\}$. Also, approximately half of his part that critiques my footnote is devoted to an explanation of my error in suggesting that he made any use of the ideas of elasticity and cross-elasticity. See id. at $\{107-13\}$. But think about it: He admits that the elasticity determines the profitability of an across-the-board price increase (and expresses annoyance at the suggestion that he did not consider this case), and he devotes significant attention in the differentiated-products merger context to how much of a firm's lost sales due to a price increase would be to the product of the firm that is its merger partner - that is, to the diversion ratio in modern parlance (mentioned in the text here), which in turn depends on the cross-elasticity. See, e.g., Kaplow \& Shapiro, supra note 3, at 1086 n.15 (offering a precise mathematical statement). Finally, I cannot help but be amused that he purports to be confused by my use of the phrase "coordinated oligopolistic pricing" that appeared in a single clause of a sentence. "Like all economists other than I, Professor Kaplow never explicitly defines what me means by 'oligopolistic pricing’....” Markovits, supra note 2, at [116\}. In addition to my detailed explanations in prior private correspondence, I have recently published three articles totaling hundreds of pages on the subject, including detailed discussions of definitions.

${ }^{31}$ The analysis implicitly assumes that the products are substitutes.

${ }^{32}$ Cameron, Glick \& Mangum, supra note 2, at $\{17\}$, assert that market definition continues to yield “important information," but do not bother to mention what that might be. 
Coordinated effects.- - Here too, the correct prescription is to stick with the homogeneous goods market. Price coordination usually involves products that are fungible, or nearly so-as suggested by theory (coordination usually becomes more complex as the dimensionality of the problem increases) and by evidence (most prosecuted price-fixing cases involve homogeneous intermediate goods). ${ }^{33}$ Therefore, to predict the price effects of the merger, we need to ascertain the degree to which the merger makes coordination more likely and how much successful coordination would increase price. The HMT is at most applicable to the latter question, but again no redefinition is involved if we do the analysis correctly. In step one, we can ask how much a hypothetical monopolist of the homogeneous goods industry would elevate price above current levels. Once we have the answer, we are done, for our question is precisely how much price would be elevated as a consequence of coordination - the many firms acting as a hypothetical monopolist of that market. We still need to weight our result by the merger's increment to the probability and degree of success, but that is another matter. Again, observe that knowledge of how much a hypothetical monopolist of some broader, heterogeneous goods market could elevate price, and of what are the HHIs before and after the merger in that market, is beside the point.

Summation.-Although the proper analysis in these three scenarios varies, some conclusions are common. First, redefining markets is inappropriate in all the cases. Second, the iterative HMT in particular is incorrect in every instance. Third, the guidelines' HHI thresholds are not useful either.

This analysis of the HMT and its standard use in merger guidelines serves two purposes. Most obviously, it suggests that current methods, if actually followed, are quite problematic and, relatedly, that if guidelines' reforms deemphasize market definition, that move is sensible at least in principle. Second, the discussion reinforces the conclusions in the first two Subsections. It has long been understood that the market definition process is imperfect, yet most have found it useful in light of the difficulty of the alternatives. Its complete failure to help—and its consistent tendency to lead us astray - in the realm of horizontal mergers, where the method has received the most attention and refinement, signals that the broader conceptual problems examined in the first two Subsections here are important and insuperable. We may think that we know, and also act as if we know, how to turn lead into gold and how to make lead without gold, but we have been fooling ourselves for ages.

${ }^{33}$ See, e.g., John M. Connor, Price-fixing Overcharges: Legal and Economic Evidence, 22 RES. L. \& ECON. 59, 136-53 (2007); Joseph E. Harrington, Jr., How Do Cartels Operate?, 2(1) Found. \& TRENDS in Microeconomics 98-102; George A. Hay \& Daniel Kelley, An Empirical Survey of Price-fixing Conspiracies, 17 J. L. \& ECON. 13, 29-39. As explained in my prior work, when there is reason to believe that a merger might enhance the ability to coordinate across different products, then the relevant product grouping is those products, not some other cluster that might be selected as the relevant market using the HMT. (Werden, supra note 2, at $\{14\}$, misses this point. But, in any case, he does not attempt to connect his discussion of this possibility to the notion of a relevant market and the use of the HMT that he defends elsewhere in his essay.) 


\section{A STANDARD REFERENCE MARKET AND MARKET SHARE THRESHOLD TESTS}

In addition to deep logical defects in the market definition approach, there are also serious problems of communication in discussing market shares and market power. Relatedly, many competition law statutes, government guidelines, court decisions, and legal treatises articulate market power requirements in terms of market shares. Regarding the latter, as discussed in Subsection I.D, this practice is common in merger guidelines, wherein the thresholds are typically denominated using HHIs. To consider an additional example, regarding the abuse of dominance in the European Union under Article 102 and monopolization in the United States under Sherman Act Section 2, a common sort of statement would be that a firm ordinarily must have a market share of at least $50 \%$ in order to be considered dominant or a monopolist.

With or without the critique in Section I, one must wonder how this practice ever came into existence, much less has persisted for so long. First, it is well understood that, for any such statements to be meaningful, one must look at the market shares in the relevant (best) market. And, long before my recent writing that demonstrates this requirement to be impossible to satisfy in an economically sensible way, it was widely appreciated that such inferences were fraught. For example, even in what is regarded to be a properly defined market, Landes and Posner, among others, have shown how a given share can imply a very wide range of market power levels because the elasticities in the formula in Subsection I.A are not limited to single values or even a narrow range of values. $^{34}$

The problem, however, runs deeper. Everyone recognizes that market shares in a given market setting need to be interpreted, and that the guidance entailed by market share threshold tests has to be understood as offering mere presumptions or rules of thumb-not rigid, sharp decision rules. Yet this acknowledgement only tells us what not to do; it fails to provide an affirmative prescription. This gap is much worse than meets the eye, for it is quite unclear what in principle is the direction of the proper adjustments, much less their magnitude. The core reason is that we really have never had any concrete idea of what market power is associated either with the market shares stated in various proffered thresholds or with the market shares in any given case. Hence, there is no way even in principle to relate one to the other, once we have abandoned any hope of doing this mechanically by taking these shares at face value.

For example, consider a 50\% presumptive share requirement for abuse of dominance. In some cases, the actual necessary share may be higher, perhaps $60 \%$ or $70 \%$, whereas there might exist other cases where the requisite market power is implied by a share of $45 \%$ or $40 \%$. Statements to this effect are familiar, but what do they mean? When is the required share higher and when is it lower? And by how much?

To make sense of the preceding example, key hurdles must be overcome. First and foremost, one would need to know how much market power is taken to be conveyed

\footnotetext{
${ }^{34}$ See Landes \& Posner, supra note 6, at 947-48, 955 tbl.1, 958 tbl.2.
} 
by the $50 \%$ market share contained in the presumptive threshold. ${ }^{35}$ But the market power tests are not stated in terms of market power levels, and instead usually only in terms of market shares. As I have explained in my previous articles, we might impute some translation between market power and market share, using a heuristic that may usefully be called a standard reference market. That is, we might all employ a common table that relates market share to market power. Perhaps a $50 \%$ share by a dominant firm is associated with a price-cost margin of $15 \%$; a $70 \%$ share with $25 \%$; a $30 \%$ share with $10 \%$; and so forth. Then - and only then — when someone refers (implicitly, as is the fashion, or explicitly) to the market power ordinarily associated with some particular market share, the reader would know what level of market power the author had in mind.

Such, of course, is not the case presently. I created this construct as a possible means of rendering discourse mutually intelligible. But, in the absence of some standard reference market being in common use, we cannot make sense of market share pronouncements to date. Perhaps we could attempt a historical reconstruction by supposing that the promulgators of all threshold tests, commentators, and courts have always had in mind the textbook "market." But there is no such thing. Perhaps they (we) all must have meant the typical or average situation. But where do we suppose such figures could have come from? Writers and readers would have had to have specified a sample of markets (whatever that means), then engaged in market definition since all agree that the shares are only meaningful in so-called relevant markets (but Section I explains that such is infeasible), and finally determined the market power associated with different shares in each relevant market, even though in the actual markets only one situation prevailed. ${ }^{36}$

Only if these obstacles are surmounted can one know how to proceed in a given case. After all, if a firm under scrutiny argues that its 55\% share is insufficient, because it conveys atypically low market power for such a share, we can only give meaning to its claim and assess its validity if we know what is the typical market power conveyed by a $55 \%$ share - and by the $50 \%$ share in our presumptive threshold. Note further that, as part of this effort, we would need to determine how much power this firm has, at which point (echoing Section I), we should naturally wonder why we are not finished: that is, once we know its actual market power, why should we be asking what market power is typically conveyed by a $55 \%$ share or any other share?

To illustrate this problem, let us examine Judge Hand's famous pronouncement in the Alcoa case that ninety percent "is enough to constitute a monopoly; it is doubtful whether sixty or sixty-four percent would be enough; and certainly thirty-three per cent is

${ }^{35}$ To keep matters simple, set to the side the important factor that the appropriate threshold might vary with the practice under scrutiny and possibly other matters. This simplification makes the case under consideration an easy one, but as we shall see, still a hopeless one.

\footnotetext{
${ }^{36}$ Werden, supra note 2 , at $\{16-17\}$, suggests that the HMT “also results in something like [a] 'standard reference market.'” He does not, however, say what it is. In it, does a 30\% share imply the ability to raise price 50\%? 5\%? $0.5 \%$ ? Note that the HMT construct asks how much further a hypothetical monopolist could raise price above existing levels. So, if the current share of a dominant firm is $100 \%$, the answer is zero. If the share of the largest existing firm is small, the answer could be literally anything. How, then, could the HMT provide even an approximate answer to the question of how much our $30 \%$ firm can raise price above the competitive level?
} 
not." 37 Consider three of the myriad possible meanings of this dictum in terms of market power:

Market Share and Market Power in Alcoa

\begin{tabular}{|c|c|c|c|}
\hline Market Share & $\begin{array}{c}\text { Market Power: } \\
\text { Low }\end{array}$ & $\begin{array}{c}\text { Market Power: } \\
\text { Medium }\end{array}$ & $\begin{array}{c}\text { Market Power: } \\
\text { High }\end{array}$ \\
\hline $33 \%$ & $1 \%$ & $5 \%$ & $25 \%$ \\
\hline $60 / 64 \%$ & $3 \%$ & $15 \%$ & $50 \%$ \\
\hline $90 \%$ & $10 \%$ & $30 \%$ & $75 \%$ \\
\hline
\end{tabular}

Starting with the "Medium" column, Hand might have thought that a market share of $33 \%$ would have implied that Alcoa could elevate price $5 \%$ above a competitive level, which he viewed to be certainly insufficient for the offense of monopolization; that a share of $60 / 64 \%$ would have implied a $15 \%$ elevation, which he thought was probably not enough; and that a share of $90 \%$ implied a $30 \%$ elevation, which he was certain sufficed. In this case, the implicit market power legal threshold that rationalizes Hand's opinion is in the neighborhood of a $20 \%$ elevation.

But, looking at the "Low" column, Hand might have envisioned much smaller levels of market power being associated with the pertinent shares, with his implicit legal threshold perhaps closer to a 5\% elevation. Or, examining the "High" column, he might have understood far greater market power levels to be involved with the stated shares, with the implicit legal threshold at about $60 \%$.

Consider what this ambiguity means for Alcoa as a precedent. In a subsequent case, we know we are to interpret market shares in context, and that a given market share may mean more or less than usual. Suppose that the share is $55 \%$, as posited in the above discussion. Under Alcoa, who wins on this issue? The short answer is that we have no idea. Now, add that further analysis reveals the share to be associated, in the present case, with a $20 \%$ price elevation. Then, if Hand had in mind the "Low" column, there is far more than enough market power; if he meant "High," there is not nearly enough; and if he meant "Medium," it is a close call.

This indeterminacy — and we have only considered three of the endless number of possible interpretations - raises insurmountable problems of application, whether for lawyers giving advice to businesses, agencies deciding when they have a plausible case, or adjudicators seeking to follow precedent. This predicament seems insoluble, for there is no way to determine what Hand meant. One possibility would be to reanalyze the aluminum industry of three quarters of a century ago to figure out the actual market power implications of these shares - no easy task and, in any event, whatever we might determine using modern methods has no necessary connection to what Hand was thinking, and the latter is relevant to interpreting the precedent. Likewise for other means of construction.

${ }^{37}$ United States v. Aluminum Co. of Am. (Alcoa), 148 F.2d 416, 424 (2d Cir. 1945). Werden, supra note 2 , at $\{20 \mathrm{n} .65\}$, quotes this passage, with approval, without mentioning my extensive critique of it. 
The foregoing, unfortunately, is not merely a nit-pick at Judge Hand. Any market share threshold in any statute, guideline, opinion, or text raises the same problems. Indeed, this was the problem at the outset in the example of a 50\% presumptive market share threshold for abuse of dominance. By reference to the above table, such a threshold might implicitly refer to a minimum price elevation of roughly $2 \%, 10 \%$, or $40 \%$ - or any other figure since those three columns do not represent the only possibilities. Market share threshold tests are, on reflection, entirely uninformative about the implicit market power requirement.

Moreover, these tests pose the aforementioned difficulty of how to determine whether the inference of market power in a given case involving, say, a 55\% share should be adjusted at all in light of the circumstances, in which direction, and by how much. It seems we would have to know both how much actual market power exists in the present case and also how much market power is implicitly required. But if we knew both of these, there would be no point in adjusting the 55\% share upward or downward, in order to then compare it with the $50 \%$ share in the test, for we would already know whether the market power in the case under consideration met the market power legal threshold.

Just as market definition and redefinition has been a subject of extensive discussion and implementation for decades, yet we really cannot make economic sense of the notion, so too market shares and market share threshold tests have been at the center of competition law rules, debates, and applications in countless cases, but without any coherent basis. Regarding market shares, the problem can in part be viewed as one involving the possibility of communication. A market share threshold test is supposed to state to the world something about how much market power is required, but it does not. Frequent arguments that market shares in one or another case imply more or less market power than meets the eye assume that there is some level of market power ordinarily associated with a given market share, which is not so. More fundamentally, it assumes that-however determined, even if by arbitrary convention - there is some degree of power that both speaker and listener have in mind, but there is not. Terms like "high" and "low" are inherently relative, and all market share discourse that is ultimately linked to market power presupposes a common benchmark, a translation table of sorts. Those who pronounce, criticize, and apply the law seem to be speaking the same language, all the while failing to communicate. ${ }^{38}$

Another useful way to view the problem is to recognize that a focus on market shares conflates two qualitatively distinct questions: How much market power exists in a given case? And how much market power is necessary to meet the legal test? The first is an empirical question, the second a matter of policy. Moreover, market shares are not in the proper units to answer either question. The amount of market power in a given case refers to the degree of profitable price elevation. Stating that a firm has a 50\% market share does not answer this question. Likewise, a market power legal threshold might indicate, say for horizontal mergers, how much of a predicted price increase is necessary

\footnotetext{
${ }^{38}$ Consider administering the following survey to your favorite competition law and policy audience. Ask a random half of them: "How much market power (measured by the extent to which a dominant firm profitably elevates price above marginal cost) is typically associated with a market share of $50 \%$ ?" Ask the other half: "What market share do you think is typically possessed by a dominant firm that can profitably elevate price by $20 \%$ ?” How widely do we imagine that such answers would vary?
} 
to trigger a challenge. Again, stating that the post-merger HHI must exceed 2500 and the increase due to the merger must exceed 200 does not answer the question. Obviously, it is impossible to respond to two distinct questions, one empirical and another about optimal policy, with a single answer. Worse, market shares answer neither one.

Applied to Hand's statement in Alcoa, we can ask whether his famous pronouncement meant to say something about how much market power existed in that case — which he had to determine to apply the legal test — or about how much market power is required in a monopolization case-which he needed to state in order to know whether the test was satisfied, and which must be taken to be his meaning if the case is to serve as a precedent. As just explained, and as illustrated above, he in fact answered neither. From his assertion, we have no idea how much market power Hand thought Alcoa possessed, and we have no clue how much market power he deemed to be legally necessary.

The competition law and policy community has communicated over the decades using market shares, both to depict something about market power in specific cases and to state legal thresholds. But market shares do neither. Recognition of this complete failure indicates that there is much work to be done, above and beyond that required by the arguments in Section I for wholesale abandonment of the market definition approach.

\section{ELASTICITIES VERSUS CROSS-ELASTICITIES}

The first two Sections, on the bankruptcy of the market definition approach and the vacuous nature of communication in terms of market shares, constitute the central critiques in my recent work. I also advance a third set of criticisms, concerning the overemphasis on and misuse of cross-elasticities in the assessment of market power. These difficulties, some of which appear also in other commentators' work, ${ }^{39}$ are not inherent in the market definition / market share paradigm, yet they seem to be induced by the perspective it entails.

When it is thought necessary to define a market, boundaries must be drawn. This in turn requires deeming particular products ${ }^{40}$ to be either in or out, a familiar and known-to-be-problematic all-or-nothing choice. Furthermore, it is common to determine whether a particular substitute is sufficiently close so as to be included by examining its cross-elasticity (or, in the language of many legal materials, interchangeability) with the central product of concern.

Substitutes' cross-elasticities do not, however, appear in the market power formula in Subsection I.A. Their relevance is due to their bearing on the magnitude of the market elasticity of demand, the first term in the denominator on the right side of that expression. The precise relationship is as follows:

\footnotetext{
${ }^{39}$ See, e.g., Schmalensee, supra note 9; Joseph J. Simons \& Michael A. Williams, The Renaissance of Market Definition, 38 ANTITRust Bull. 799 (1993); Gregory J. Werden, Demand Elasticities in Antitrust Analysis, 66 ANTITRUST L.J. 363 (1998). Even though I acknowledged that part of this critique is not new, Cameron, Glick \& Mangum, supra note 2, at $\{1\}$, seem to think I am unaware of this, and yet, at the same time, advocate the approach I criticize because cross-elasticities are helpful in defining markets.

${ }^{40}$ Again, analogous reasoning is applicable to geographic market definition.
} 


$$
\left|\varepsilon_{d}\right| \equiv\left|\varepsilon_{11}\right|=1+\sum_{i=2}^{N} \frac{R_{i}}{R_{1}} \varepsilon_{i 1} .
$$

On the left side we have the market elasticity of demand, which for notational clarity in this context is helpfully restated as the elasticity of demand for the initial product (designated as product 1) with respect to a change in its own price. This own-price elasticity, in turn, equals 1 plus the revenue-weighted sum of the cross-elasticities of demand with all of the other $N$ products. ${ }^{41}$ The revenue weight for a product $i\left(R_{i}\right)$ is the ratio of expenditures on that product to expenditures on our initial product, and the crosselasticity $\left(\varepsilon_{i 1}\right)$ considered here is the percentage change in the quantity of product $i$ as the price of product 1 is increased.

Although substitutes' cross-elasticities are relevant to the market elasticity of demand in our original market, there are a number of reasons that we should not ordinarily focus on cross-elasticities. First, information on the overall demand elasticity is what ultimately matters, it subsumes the cross-elasticities for all other products, and such information is often as easy or easier to obtain, and as or more reliable, than is information on particular cross-elasticities.

Second, focus on specific cross-elasticities is incomplete because the crosselasticities of all other products are also relevant. Consideration of only the closest substitutes could omit a great deal. To illustrate, one might in one case include a single, close substitute and in another case omit a dozen more distant substitutes even if the latter collectively are more powerful. For example, if revenue weights were equal and the cross-elasticities of the dozen were each one-fourth that of the single, close substitute, then the dozen together would have three times the impact of the single, close substitute. In some instances such omission may not be a problem if the inclusion of close substitutes is employed merely to form a lower bound on the market elasticity of demand, which if sufficiently large would rule out anticompetitive concerns. ${ }^{42}$

Third, inclusion implies overstatement of the restraining force of the substitutes because even close substitutes generally are not perfect substitutes. This point is related to the need to interpret market shares in the redefined market, which Subsection I.A indicates is possible only by undoing the redefinition and returning to the homogeneous goods market.

Fourth, the importance of the revenue weights is often implicitly ignored. Crosselasticities indicate percentage changes in demand for a substitute, but the importance of

\footnotetext{
${ }^{41}$ The explanation for the 1-plus term is that if, say, the demand for none of the other products changed when the price of product 1 rises, then the elasticity of demand for that product would be 1 , not 0 : since the same revenue continues to be spent on product 1, a one percent increase in price implies a one percent fall in quantity (literally so for infinitesimal changes).

${ }^{42}$ If some of the omitted products are complements, one would not obtain a true lower bound, but often it would be plausible that the omitted group, taken as a whole, was a net substitute, in which case a lower bound would be formed. Cameron, Glick \& Mangum, supra note 2, at $\{22\}$, also assert that they "have not been able to identify any cases where a court has overestimated a defendant's market power because it failed to identify a set of low cross-elasticity competitors that collectively were a constraint on the defendant." I suspect some defendants would disagree. More to the point, are these authors really telling us that they have taken thousands of cases, independently collected data that was not considered, and assessed whether taking it into account would have influenced the conclusions reached?
} 
a given percentage change depends on the base: hence the revenue weights. For example, a substitute with a cross-elasticity of 5 but a revenue weight of 0.1 has only half the impact of a substitute with a cross-elasticity of 1 but a revenue weight of 1.0. One type of mistake is that we might be led to exclude a product that has a fairly low crosselasticity when its large revenue weight indicates that it imposes a strong restraint on price increases of the product in question. On the other hand, when we include products with large revenue weights, shares drop dramatically, which can lead to substantial understatement of market power, as illustrated by the second part of the unilateral effects example in Subsection I.D. Moreover, the magnitude of the resulting errors can be huge: the revenue weights in the above example differ by a factor of ten, but when one contemplates the range of goods and services in an entire economy, these weights can differ by many orders of magnitude.

All these difficulties are avoided by focusing on the market elasticity of demand in the original market rather than attending to the cross-elasticities of demand for various particular substitutes. At this point, we can see that there is a close affinity between the market definition approach and the mistaken focus on cross-elasticities. If one thinks it necessary to define a market, and if that process is understood as a determination of which goods are inside the market and which are outside, then it seems necessary to inquire whether or not each plausible substitute is sufficiently close, which in turn leads to an inquiry into its cross-elasticity. In contrast, if the direct question of market power is kept front and center in the inquiry, then one is led to ask about the market elasticity of demand rather than to focus on particular cross-elasticities. (Also, when one does look at cross-elasticities, under a direct assessment one is led to use the above formula to ascertain their impact on market power.)

The foregoing criticism does not, however, imply that cross-elasticities per se are always irrelevant. Initially, as already explained, the market elasticity is an aggregate of the cross-elasticities, and sometimes estimating some key cross-elasticities - and applying the revenue weights - will enable a useful lower bound estimate of the overall demand elasticity. Additionally, in certain settings particular cross-elasticities are useful. In predicting the price effects of differentiated products mergers, as discussed in Subsection I.D, one needs to know the diversion ratio between the merging firms' products, which in turn is indicated by the (revenue-weighted) cross-elasticities. ${ }^{43}$ Relatedly, if an alleged exclusionary practice is directed at particular substitutes, its potential impact is similarly determined. ${ }^{44}$ Therefore, cross-elasticities sometimes are useful, but none of these valid applications involve market (re)definition.

\section{CONCLUSION}

In recent articles, I have advanced the proposition that the market definition / market share paradigm should be abandoned entirely. I reach this conclusion for a number of reasons that have now been explained:

\footnotetext{
${ }^{43}$ See, e.g., Farrell \& Shapiro, supra note 30.

${ }^{44}$ See Kaplow \& Shapiro, supra note 3, at 1185-86.
} 
1. There exists no valid way to infer market power from market shares in redefined (non-homogeneous-goods) markets, that is, short of undoing the market redefinition.

2. There exists no useful way to define markets.

a. In defining the relevant market, one needs a criterion, and the most appealing one is to choose that which is best in terms of leading to the most accurate market power inference.

b. But there exists no way to do this without already having in hand one's best estimate of market power, rendering the market definition exercise pointless.

c. Worse, when one does use the relevant market to infer market power, one may generate legal results that are avoidably inferior to those one would achieve had one simply stuck with one's best estimates of market power.

3. Neither the complexities of the world nor the difficulties of formulating market power estimates in various settings suffice to repeal the laws of logic or to vest analysts and decision-makers with magical powers.

4. The market definition approach, as embodied in the hypothetical monopolist test or otherwise, can only subtract value in analyzing mergers in any of the standard settings.

5. Communicating about market power in the language of market shares utterly fails. Specifically, market power thresholds cannot meaningfully be stated as market share tests.

6. Important errors can result from overemphasis on cross-elasticities of demand rather than the elasticity of demand, and these errors are encouraged by the market definition paradigm.

These problems are matters of logic rather than conclusions reached by making empirical, pragmatic judgments. Nevertheless, many resist them, and this resistance is understandable. The market definition approach has been with us for a long time. And the alternative, requiring direct inquiry into market power, is often daunting. (Of course, in light of point 2, we have been fooling ourselves in thinking that we have been avoiding it.)

Denial, however, is no answer. It cannot make the challenges disappear. There is no Camelot to restore: there never was and never could be. Accordingly, we need to get on with the hard work of improving ways to determine how better to assess market power in various settings. ${ }^{45}$

\footnotetext{
${ }^{45}$ In addition to making more direct and effective use of firms' internal records and the views of important market players, work by economists in recent decades has made great progress developing econometric techniques. See, e.g., Jonathan B. Baker \& Timothy F. Bresnahan, Empirical Methods of Identifying and Measuring Market Power, 61 ANTITRUst L.J. 3 (1992); Jonathan B. Baker \& Timothy F. Bresnahan, Estimating the Residual Demand Curve Facing a Single Firm, 6 INT’L J. INDUS. ORG. 283 (1988); Gregory J. Werden \& Luke M. Froeb, Unilateral Competitive Effects of Horizontal Mergers, in HANDBOOK OF ANTITRUst ECONOMics 43 (Paolo Buccirossi ed., 2008); MichaEL D. Whinston, LECTURES ON ANTITRUST ECONOMICS 100-14 (2006). (Indeed, one of my critics, Gregory Werden, supra note 2, is among those who have made important contributions in this realm.) It is hoped that the present critique will increase the sense of urgency of this mission and thereby accelerate it.
} 
